\title{
WHAT IS PUBLISHING?
}

GROUP 1

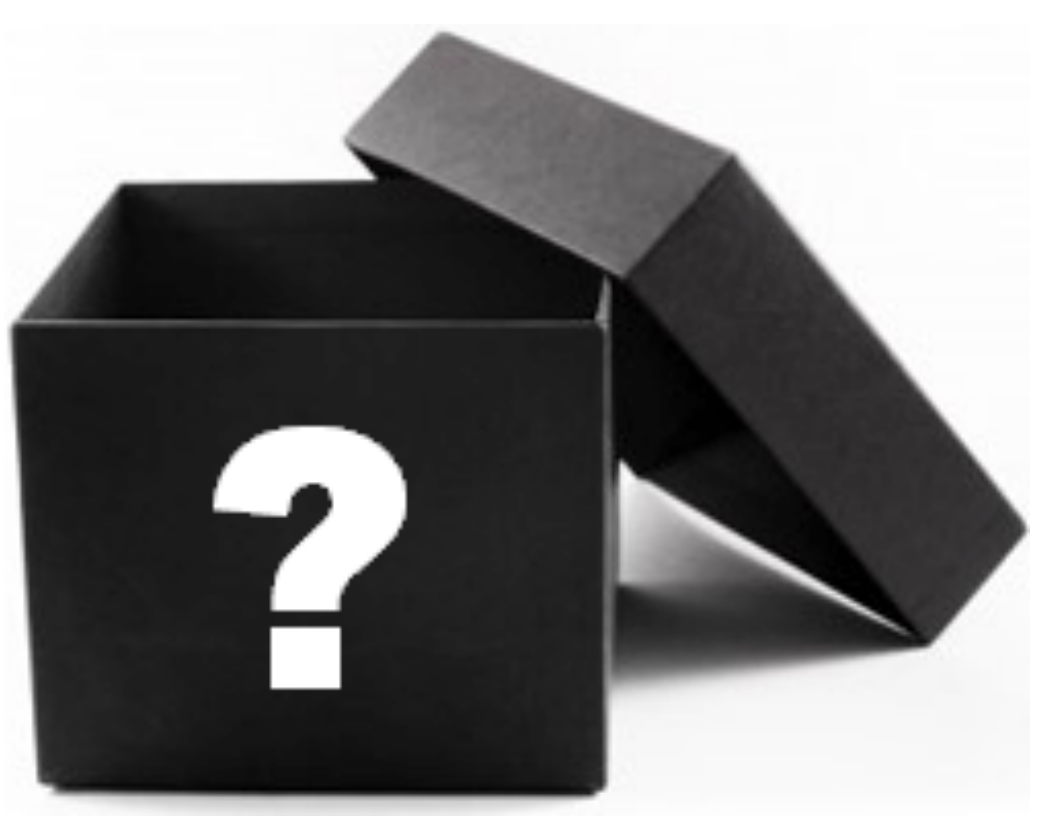




\section{How do we provide the greatest benefit of the scholarly enterprise to a global society in a sustainable way?}




\section{What can publishing become?}

We've been talking about this for a long time....

"A day will come when journals will be superseded as a means of publishing new research."

- Theodore "Robbie" Fox (1965), Editor of The Lancet 1944-1964

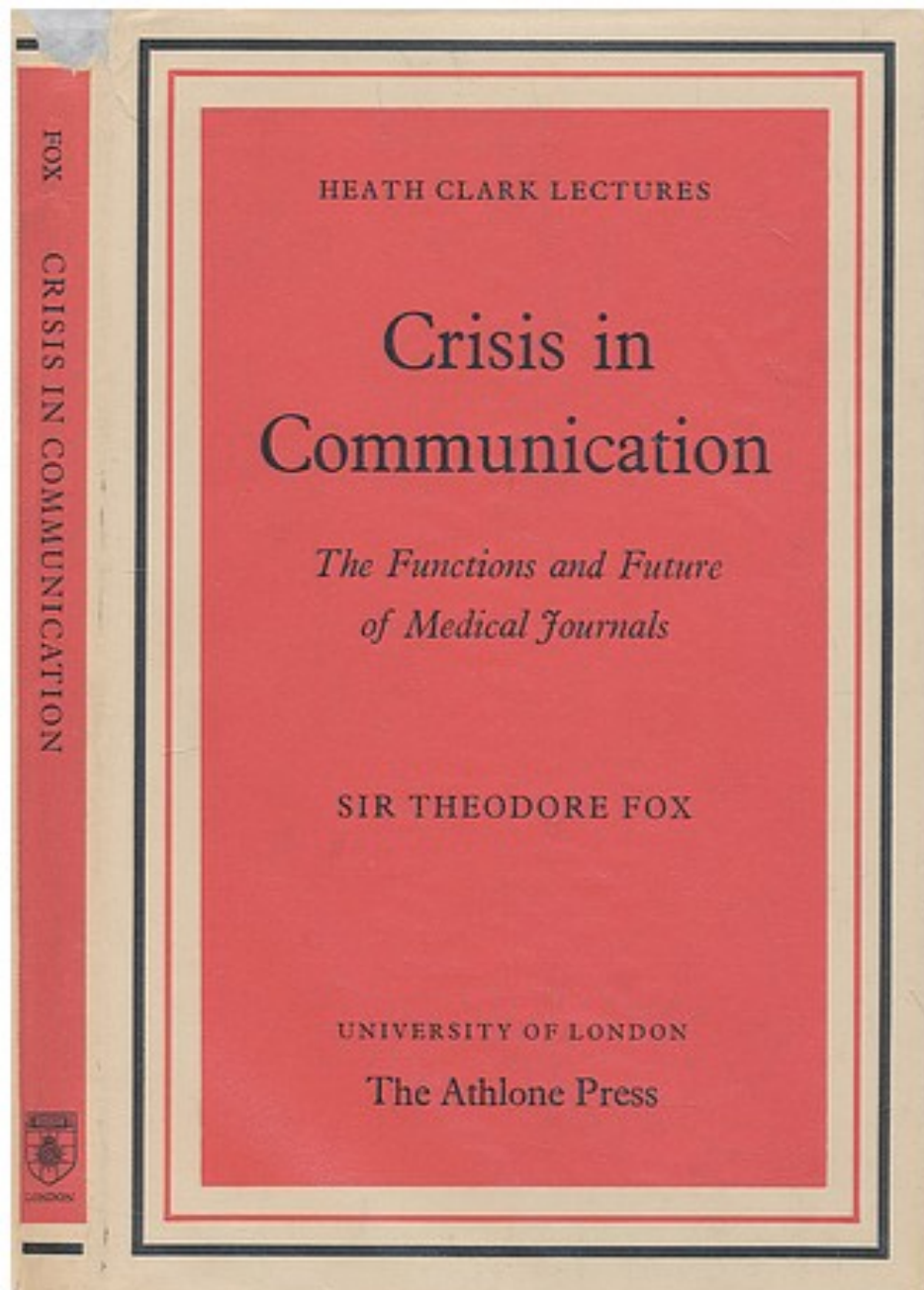




\section{DEFINING THE PROBLEM}

- Our notion of "publishing" was concrete, mechanistic, and monolithic -- a shared infrastructure with definitive boundaries.

- This paradigm is still in operation; it has been disrupted by the web, not transformed.

- Academic publishing models are largely the same as 30 (or even 350 ) years ago. Are we okay with this pace? 


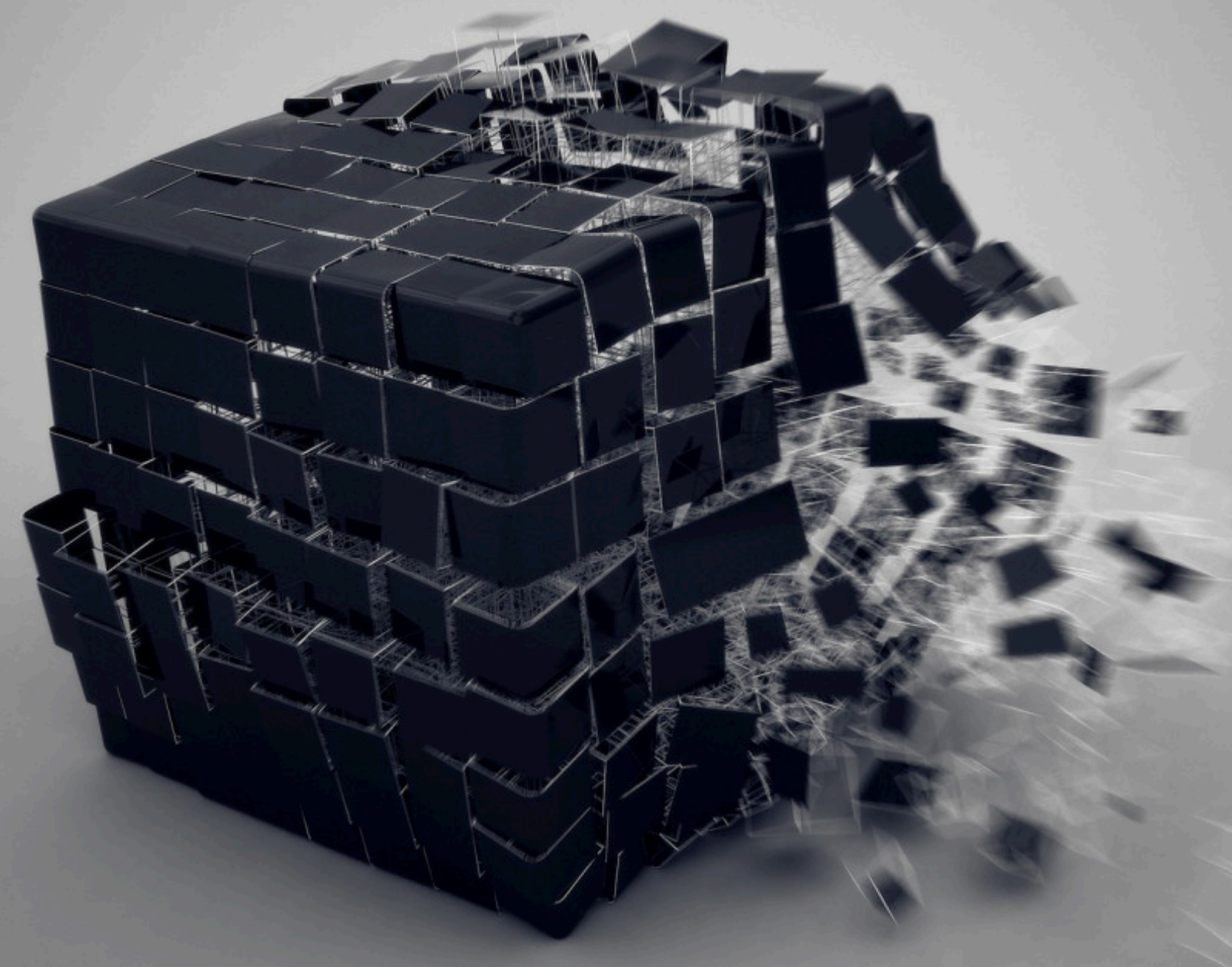




\section{WHAT IS PUBLISHING?}

... a process that creates/captures and makes discoverable artifacts of knowledge in order to facilitate the use and reuse of scholarship on a global scale. It enables research communities to build upon the work of others and provides a venue for evolving discourse. 



\section{OBSTACLES}

Infrastructure Limitations

Authorship, Attribution Credit

Standards \& Rewards: Hiring, Promotion

Publishing:

Pace of Information

Processing and

Peer Review 


\section{WHAT IS THE MISSION?}

- For everyone who needs access to scholarly information to have it;

- For authors to have choices that they don't currently have;

- To encourage disruption in business models by unbundling the research process and opening up new services around it;

- To encourage entry of new individuals and organizations into the knowledge ecosystem. 


\section{Can we 'UNBUNDLE' publishing?}

Single stable artifact (journal article or monograph) ---> multiple research objects

Monolithic (one-size-fits-all) black box ---> a menu of unbundled service offerings
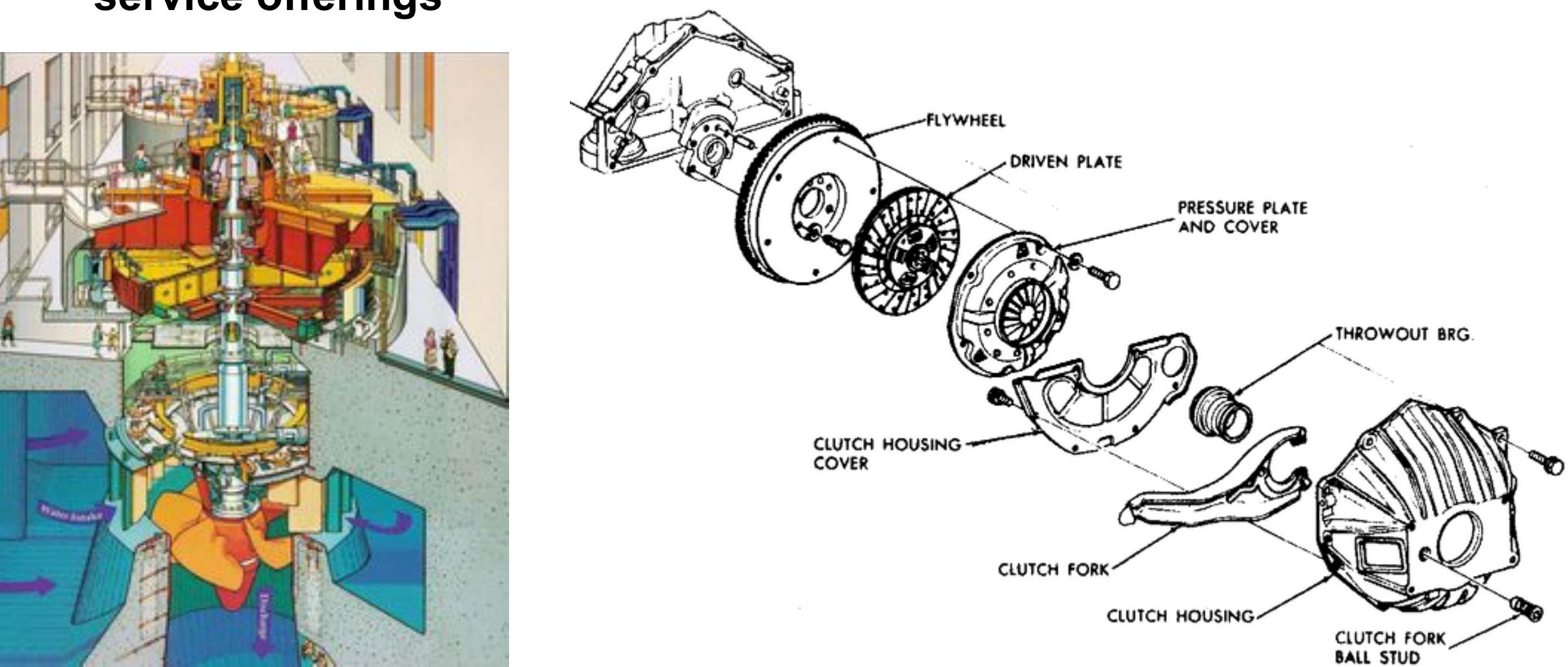


\section{CALL TO ACTION - NEXT STEPS}

Within our context of publishing as an interdependent ecosystem...

- Audit what exists for and evaluate each module of an unbundled publishing 'service'

- Form a working group on open source, standardized, federated, modular infrastructures

- e.g. VIVO published works ontology, CrossRef, ORCID, Collaborative Knowledge Foundation, Ambra 
How do we provide the greatest benefit of the scholarly enterprise to a global society in a sustainable way?

What is publishing? -> What will publishing be? 


\section{OUR TEAM}

- Amy Brand, Director, The MIT Press

- James Butcher, Publishing Director, Nature Journals

- Meg Buzzi, Director, Opus Program, UCLA

- Kathleen Fitzpatrick, Director of Scholarly Communication, Modern Language Association (MLA)

- Ann Gabriel, Vice President, Academic \& Research Relations, Elsevier

- Rikk Mulligan, Program Officer for Scholarly Communication, Association of Research Libraries (ARL)

- Vivian Siegel, Director of Education and Training, Global Biological Standards Institute

- Matt Spitzer, Community Manager, Center for Open Science (COS)

- Jamie Vernon, Director of Science Communications and Publications at Sigma Xi and Editor-in-Chief, American Scientist

\section{Supporting notes:}

https://docs.google.com/document/d/1ChYsQ9RxcSTuYv1PaLFnDXX3zOPinrnl0EUWkP-QXCs/edit? usp=sharing 